\title{
ASPECTOS ULTRAESTRUTURAIS DO PROCESSO DE DIVISÃO DO TOXOPLASMA GONDII
}

\author{
Wanderley de Souza *
}

Neste trabalho é feita uma revisão sobre alguns aspectos biológiros do Toxoplasma gondii, principalmente sobre a ultraestrutura da forma interfásica $e$ as modificações ultraestruturais que ocorrem no parasito durante o seu processo de divisão.

Considera-se inicialmente o processo de divisấo binária admitindo-se, porém, a possibilidade de que as imagens interpretadas como sendo de divisão binária representem estägios da divisão por endodiogenia.

Quanto à endodiogenia descrevem-se as alterações nue ocorrem na "parasito mãe" durante o processo de formação dos dois "parasitos filhos". Este prozesso é semelhante no Toxoplasma gondii, Besnoitia jellisoni, Sarcocystis tenella e Frenkelia. Discute-se a possibilidade da formação de mais de dois "parasitos filhos" por um processo de endopoligenia, bem como o processo de esquizogonia. Os resultados mais recentes mostram que não existe esquizogonia nas formas vegetativas do Toxoplasma gondii, sendo que as imagens interpretadas como tal, ao microscópio ótico, são o resultado de endodiogenias sucessivias em aue os endozoitas formados permanecem ligados entre si pela regiāo posterior. A esquizogonia é, no entanto, encontrada nas formas que se desenvolvem no interior de células epiteliais do intestino do gato, que é o hospedeiro definitivo do Toxoplasma gondii. Discute-se o conceito de esquizogonia, comparando-o em três protozoários: Eimeria bovis, E. callospermophili e Plasmodium juxtanucleare, que apresentam diferenças entre si quanto ao processo de iniciação da individualização dos "parasitos filhos". Refere-se à recente hipótese que considera a endodiogenia como o processo fundamental de divisão dos esporozoários, ocorrendo na fase final da esquizogonia.

Finalmente é acentuado o papel que a microscopia eletrônica aliada às modernas técnicas de citoquim:ca e imunocitoquím:ca poderá desempenhar no sentido de um melhor conhecimento da biologia do Toxoplasma gondii $e$ da fisiopatogenia da Toxoplasmose.

\section{INTRODUÇÃO}

Toxoplasma gondii, agente etiológico da toxoplasmose, foi descoberto em 1908 independentemente por Splendore em são
Paulo e por Nicolle et Manceaux em Tunis. Durante muito tempo discutiu-se a sua posição taxonômica; recentemente foi incluido entre os coccídeos. Ele foi inicialmente considerado como um protozoário

* Bolsista do Conselho Nacional de Pesquisas.

Laboratório de Cultura de Tecidos e Labcratório de Microscopia Eletrônica do Instituto de Biofísica da U.F.R.J., Centro de Ciências Médlcas - U.F.R.J., Cidade Universitária Rio de Janeiro - GB. Recebido para publicação em 29_12-1973. 
com ciclo de vida simples, apresentando formas vegetativas obrigatoriamente intracelulares. No entanto, os resultados recentes mostram que o seu ciclo de vida é complexo, apresentando formas esquizogônicas e gametogônicas que se desenvolvem no epitélio do intestino do gato, levando à formação de oocistos que são liberados pelas fezes desse animal $(10,20)$.

Os primeiros estudos realizados com o Toxoplasma moztraram que ele necrssitz de uma célula hospedeira para a sua sobrevivência e apresenta um comportamento semelhante ao apresentado por alguns virus (40). Diversos estudos foram feitos com o objetivo de explicar a razão desta dependência do parasito pelo citoplasma de uma célula hospedeira.

Várias tentativas foram feitas no sentido de se encontrar um meio no qual o Toxoplasma pudesse ser cultivado, e que permitisse a obtenção de quantidades suficientemente grandes de parasitos, que possibilitassem a realização de estudos bioquímicos. Infelizmente todas as tentativas realizadas até o mcmento, visando à obtenção de um meio sintético para o cultivo do Toxoplasma, foram negativas. Nessas tentativas foram utilizados meios usualmente aplicados ao cultivo de bactérias, fungos e protozoários. Destaque especial deve ser dado à verificação inicial feita por Levaditi et al (23) de que o Toxoplasma existente em fragmentos de cérebro de pintos e pombos com toxoplasmose, poderia infectar tecidos normais colocados em íntimo contato com o tecido parasitado num sistema de cultura de tecidos. Meyer et al $(3,15,26,32)$ confirmaram esses resultados e, aperfeiçoando a técnica, mostraram que o Toxoplasma pode ser mantido indefinidamente em culturas de tecido. Com esta técnica estudaram a penetração do parasito na célula, sua multiplicação, formação de rosáceas e rompimento da célula hospedeira, liberando parasitos para o espaço intercelular. Estes aspectos podem ser melhor apreciados no recente estudo micrccinematográfico, em contraste de fase, realizado por Meyer e de Oliveira Musacchio (32). Tomando por base os trabalhos iniciais de Meyer et al, grande número de autores passou a utilizar a cultura de tecidos como um modelo de toxoplasmose experimental, quer para estudos imunológicos, quer para teste de substâncias com possivel ação letal sobre o parasito. Com a evolução da técnica de cultura de tecidos surgiu a cultura de células isoladas por tripsinisação e que passou a ser também utilizada para o cultivo do Toxoplasma.

Logo no início do desenvolvimento da microscopia eletrônica, esta técnica foi aplicada ao estudo do Toxoplasma. Meyer e de Andrade Mendonça (27), realizaram as primeiras observaçōes do parasito in toto. No entanto, devido à espessura do parasito, não havia suficiente penetração do feixe eletrônico de modo que pouca informação pode ser obtida. Posteriormente Gustafson et al (16) e outros autores $(4,5$, $11,12,21,22,28,31,33,34,37,43,45,50,51$, 54-56) utilizando a técnica dos cortes ultrafinos, mostraram que o Toxoplasma nāo só apresenta praticamente todas as estruturas conhecidas em outros protozoários, como também dispõe de estruturas que lhe são características. A utilização recente das técnicas de biologia celular ao estudo do Toxoplasma tem fornecido alguns dados, ainda que preliminares, mas que começam a elucidar algumas das dúvidas ainda existentes.

Inicialmente acreditou-se que o Toxoplasma se dividia pelo processo de fissão binária, tal como ocorre em vários protozoários. Foi também descrito um processo de divisão nuclear múltipla, do tipo esquizogônico. Mais recentemente observou-se um tipo especial de divisão em que se formam dois parasitos filhos dentro do parasito mãe. Tal processo é chamado de endodiogenia. Nas observações usualmente realizadas em esfregaços, cortes histológicos e mesmo in vitro $\mathrm{em}$ culturas de tecido, com o microscópio de contraste de fase, não é possível se obter uma idéia completa do processo de divisão. No caso particular da divisão por endodiogenia descrita por Goldman et al $(13,14)$, as imagens são convincentes devido à técnica especial de impregnação pelo proteinato de prata, usada pelos auotres.

Certamente só a microscopia eletrônica pode esclarecer, até certo ponto, o processo de divi:ão do Toxoplasma. Como este processo envolve modificaçōes ultraestruturais do parasito é indispensável uma descrição, ainda que resumida, da ultraestrutura do Toxoplasma gondii na sua forma interfásica. 


\section{ASPECTOS ULTRAESTRUTURAIS DO TOXOPLASMA GONDII}

Ao microscópio ótico observa-se que o Toxoplasma tem uma forma de "banana". O seu comprimento varia entre 4-8 $\mu \mathrm{m}$; a sua largura, em torno de $2-4 \mu \mathrm{m}$ (Fig. 1 e 2).

a) Envoltório do parasito - O Toxoplas$m a$ é envolvido por um sistema de membranas constituido por uma membrana externa de natureza trilaminar cuja es-

pessura é de 70-80 A e que o envolve completamente. Logo abaixo, a uma distância variável (entre $100-200 \AA$, encontra-se uma membrana média cuja espessura é de $180 \AA$ e que não envolve completamente o parasito, estando interrompida na porção mais apical da regiāo anterior (complexo apical) e ao nível de uma estrutura existente na parte lateral do parasito que tem sido designada por citóstomo. Ao nível dessa estrutura, a membrana externa sofre apenas uma pequena depressāo. Segundo Vivier e Petitprez (52) a membrana interna é na realidade constituída por duas, uma módia e uma interna; as duas permanecem sempre juntas, havendo um espaço entre elas variável em torno de 25 a $75 \stackrel{\circ}{\text { A. }}$ Tanto a membrana média como a interna, apresentam estrutura trilaminar cuja espessura é de $75 \stackrel{\circ}{\mathrm{A}}$. Como estas duas membranas estão sempre juntas, o termo mombra interna será utilizado para designá-las.

Um citóstomo é hoje considerado como uma abertura no corpo celular, visivel ao microscópio ótico, através do qual o parasito se alimenta (24). A estrutura observada no Toxoplasma, apresentando pequenas dimensões $(0,04-0,05 \mu \mathrm{m}$ de diâmetro por $0,15 \mu \mathrm{m}$ de profundidade) nāo é visível ao microscópio ótico e nem o seu papel na ingestão de alimentos está perfeitamente demonstrado; portanto não se enquadra na definição de citóstomo. Ela é também chamada por alguns autores de "micropyle", denominaçāo essa que devia ser utilizada apenas para designar uma abertura (ou posição de abertura) existente na parede de um oocisto. O termu mais correto para designar essa estrutura no Toxoplasma seria "micropore", definido por Levine (24) como sendo uma abertura lateral de um esporozoita ou outros estágios encontrados em protozoários de sub- filo Apicomplexa, visível apenas com o microscópio eletrônico e utilizado em alguns parasitos para a ingestāo de alimentos. Estudos de Rudzinska et al (39), Aikawa et al (1) em parasitos da malária, demonstram que esta estrutura é utilizada para a ingestão de material da célula hospedeira (hemácea) que pode ser facilmente distinguido do citoplasma do parasito devido a alta densidade eletrônica do citoplasma da hemácea. No entanto, no caso do Toxoplasma ainda não foi possível demonstrar que este fenômeno também ocorra, embora sejam encontradas no citoplasma do parasito certas estruturas que correspondem aos vacúolos digestivos exlstentes nos parasitos da malária.

b) Regiäo Anterior (complexo apical) Nessa regiāo encontra-se uma estrutura cilíndrica, o conóide, constituída por 3 anéis polares. Partindo do anel polar inferior originam-se 22 microtúbulos que, dispondo-se na periferia, logo abaixo da membrana interna, projetam-se para a região posterior do parasito onde terminam livremente (4). Esses microtúbulos podem alcançar um comprimento em torno de $8 \mu \mathrm{m}$. Apre entam uma espessura variável entre 180-230 A, com estriações transversais cuja periodicidade é de cerca de 80 A. Os microtúbulos foram interpretados como sendo de natureza contrátil e responsáveis pela movimentação do parasito, principalmente quando ele está fora da célula, no espaço intercelular, procurando penetrar no interior de uma nova célula hospedelra. Nas preparaçōes em que se utiliza a técnica de inclusāo e corte ultrafino os microtúbulos nem sempre podem ser bem visualizados. A técnica mais indicada para a sua visualização é a de coloração negativa, com ácido fosfotúngstico, aplicada a uma suspensão de parasitos integros ou submetidos a choque osmótico (4) (Fig. 5).

Já pela técnica dos cortes é possivel ver que o conóide é constituído por 3 anéis polares, apresentando uma estrutura quadriculada (Fig. 2). Quando examinado pela técnica de coloração negativa verifica-se que os microtúbulos que têm origem no primeiro anel polar, projetam-se também para a parte superior do conóide de modo a se cruzarem, conferindo ao conóide o aspecto quadriculado acima mencionado. Os microtúbulos encontram então o segun- 
do anel polar e daí projetam-se para o terceiro anel polar (porçāo mais anterior do conóide), na parede da qual parecem estar dispostos paralelamente e em intimo contato. Dessa forma, podemos considerar - conóide como uma estrutura cilindrica cuja parede é constituída por microtúbulos (5) (Fig. 7). Em algumas ocaciōes observa-se junto ao conóide a presença de vesículas do tipo pinocitótico, sugerindo a existência de um processo de pinocitose nessa região (55).

Além do conóide encontram-se na região anterior, várias estruturas eletrodensas, delimitadas por membrana. Apresentam uma base mais larga, localizada na regiāo média do parasito, e se afinam à medida que se dirigem para a região anterior, chegando a penetrarem no conóide (Fig. 2 e 7). Algumas vezes elas apresentam um aspecto vesicular. Estruturas semelhantes têm sido encontradas em grande número de parasitos, recebendo diferentes denominações. Gustafson et al (16) ao descrevê-las pela primeira vez no Toxoplasma, chamaram-nas de toxonemas, pensando serem elas estruturas caracteristicas do Toxoplasma. No entanto, estruturas semelhantes foram descritas posteriormente em outros protozoários onde receberam desínações tais como corpos densos, lankesteronemas, eimerionemas e organela pareada, sendo esta última denominação muito utilizada para os parasitos da malária, por apresentarem apenas duas destas organelas (41). Mais recentemente tem sido utilizado o termo roptria para designá-las numa tentativa de uniformização (24). Sheffield e Melton (50) descrevem no Toxoplasma a existência de certas estruturas também localizadas na regiāo anterior; são chamadas de micronemas. Segundo eles tais estruturas devem estar relacionadas com as roptrias ou mesmo, como aceito pela maioria dos autores, serem estágios diferentes de uma mesma organela.

O papel funcional das roptrias ainda não está suficientemente esclarecido. Segundo alguns autores elas estão relacionadas com o processo de penetração do parasito. Alguns trabalhos têm mostrado que, quando se adiciona hialuronidase ou lisosima ao meio de cultura para o cultivo de células e as infecta com Toxoplasma, o número de parasitos que penetram nas células corresponde ao dobro da situaçāo controle. Esse fato apoia a idéia de que - Toxoplasma no seu processo de penetração ativa, lance mão de substâncias com ação semelhante à da hialuronidase (25). Como a única estrutura existente no Toxoplasma que tem um aspecto de secreção são as roptrias, e levando-se em consideração a sua localização, admite-se que elas sejam reservatórios de substâncias proteolíticas. Estudo citoquímico recente, com o uso do microscópio eletrônico, demonstra a presença de mucopolissacarídeos e fosfatase ácida nestas organelas (55). Em trabalho recente, sugerimos que o Toxoplasma penetra no interior das células liberando substâncias proteolíticas existentes nas roptrias, graças a uma contração dos microtúbulos, que constituem a parede do conóide, que desempenharia o papel de um esfincter (5). Embora neste caso estejamos raciocinando em função de um mecanismo ativo de penetração, não excluímos a possibilidade, sem dúvida alguma existente, que também haja penetração passiva do parasito, isto é, através de um processo de fagocitose por parte da célula (22).

c) Outras Regióes - o núcleo do Toxoplasma está localizado na região central com tendência à região posterior. de forma mais ou menos esférica e envolvido por dupla membrana que apresenta poros. A cromatina encontra-se espalhada por todo o núcleo; um ou dois nucléolos podem ser vistos às vezes localizados no centro, e às vezes acolados à membrana nuclear (F:g. 2). Recentemente foi descrita a presença de um centriolo, constituído por 9 microtúbulos periféricos e uma estrutura tubular central, e localizada na região anterior, próximo ao núcleo (55). Tal ocorrência foi por nós confirmada (Meyer e de Souza, dados não publicados). Este centríolo é semelhante ao descrito em Eimeria necatrix durante o seu desenvolvimento esquizogônico no epitélio intestinal da galinha doméstica $(7,8)$. Em formas proliferativas intracelulares do Toxoplasma em culturas de tecido encontramos a presença de uma placa eletrodensa semelhante à descrita em parasitos da malária (Meyer e de Souza, dados nāo publicados) de onde partiam vários microtúbulos que pareciam constituir um fuso. 


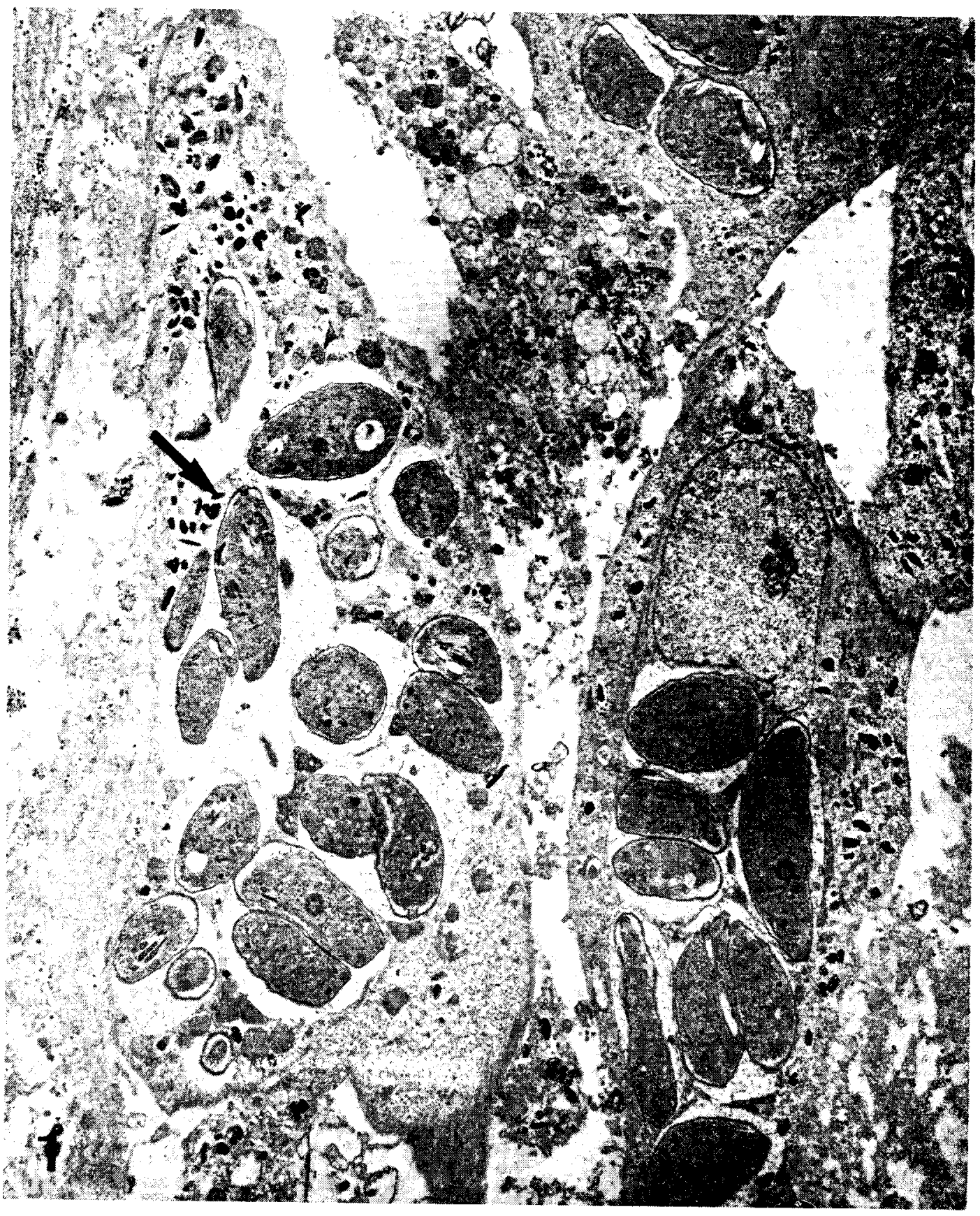


Figura 1 - Toxoplasmas no citoplasma de céluias do epitélio pigmentar da iris de embriăo de pinto mantido em culturas de tecido. Os parasitos se multiplicam nos vacúolos citoplasmáticos da célula hospedeira de manetra desordenada, sem formarem rosáceas. No citoplasma da célula hospedeira observa-se a presença de grânulos eletrodensos que correspondem aos grânulos de melanina existentes na célula pigmentar.

Material fixado em glutaraldeido $2,5 \%$ e pós-fixado em tetróxido de ósmio $1 \%$.

Aumento: $3.750 \mathrm{x}$ 


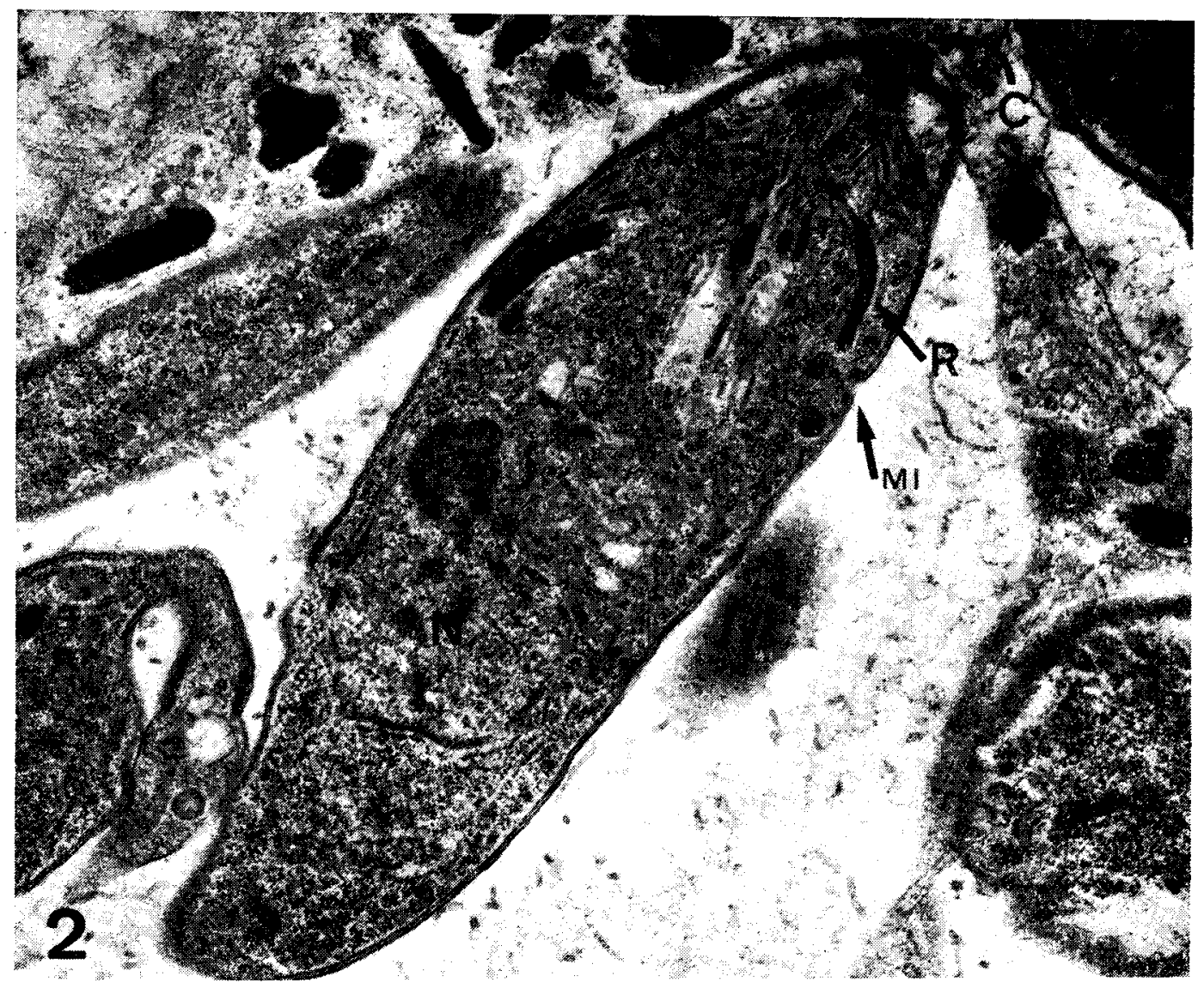

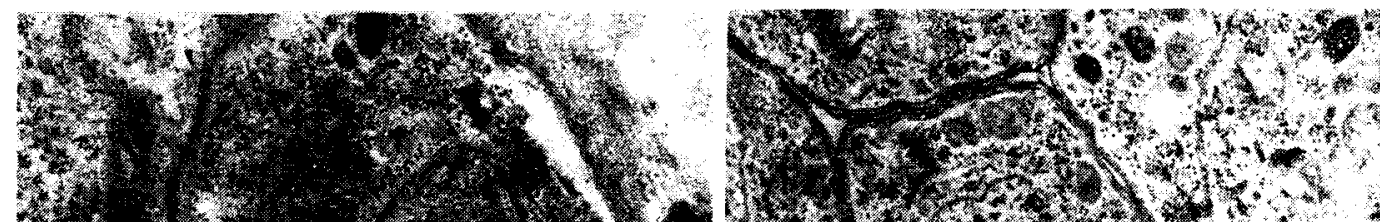

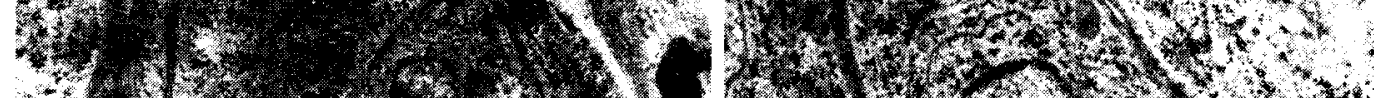
-5
3

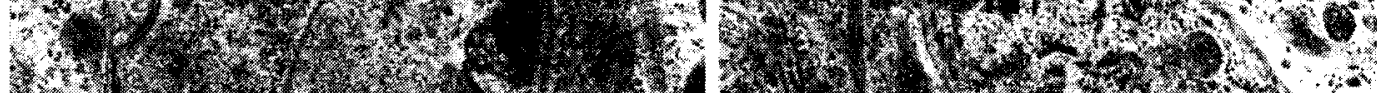

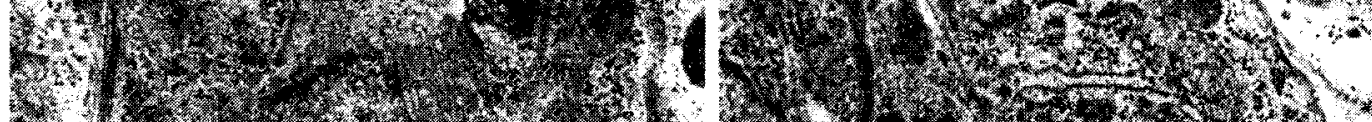

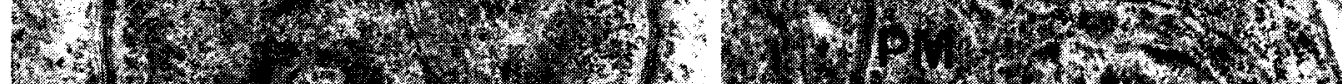

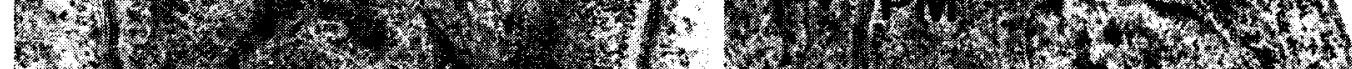

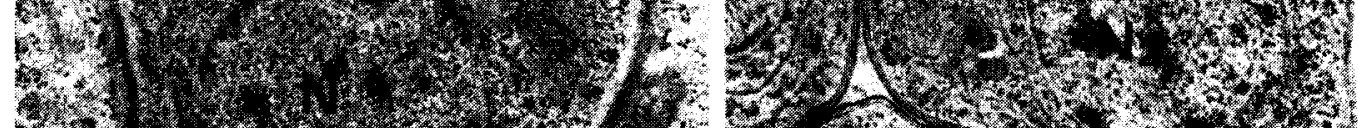

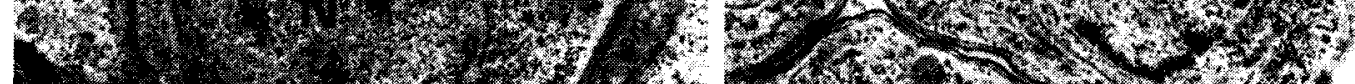

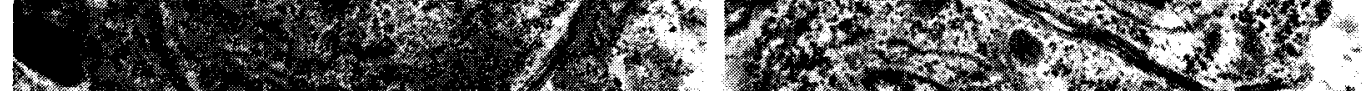

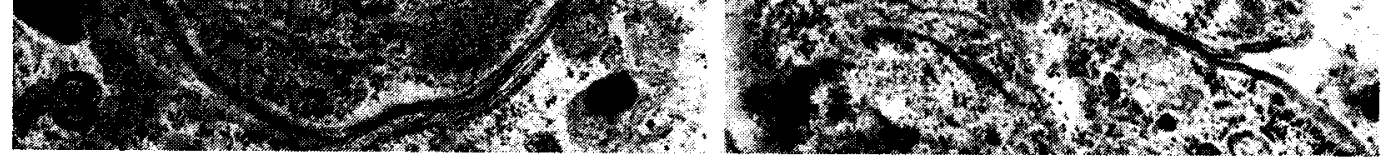


Figura 2 - Maior aumento da região assinalada na figura anterior $(\rightarrow)$ mostrando um Toxoplasma em corte longitudinal. Vê-se o conotde (C), "micropore" (MI), estruturas eletrondensas correspondente às Roptrias (R), Núcleo $(N)$ e Citoplasma. Aumento: $25.000 \mathrm{x}$.

Figura 3 - Toxoplasma em divisão mostrando a formaçáo da membrana espessa (seta) logo acima do núcleo do parasito (N). Aumento: $20.000 x$.

Figura 4 - Corte transversal do Toxoplasma em divisáo. Observa-se a presença de dois núcleos $\left(\mathrm{N}_{1}\right.$ e $\mathrm{N}_{6}$ ) incorporados a dois "parasitos filbos" que já estão delimitados por uma membrana (setas), permanecendo no interior do "parasito mãe" (PM). Aumento: $20.000 \mathrm{x}$. 


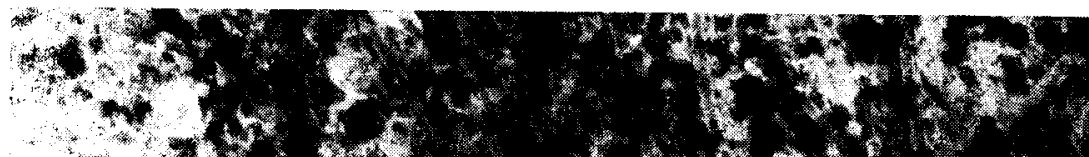

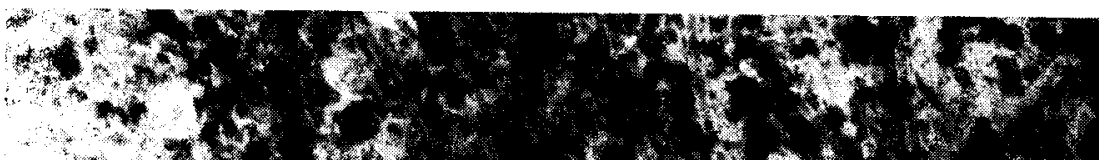

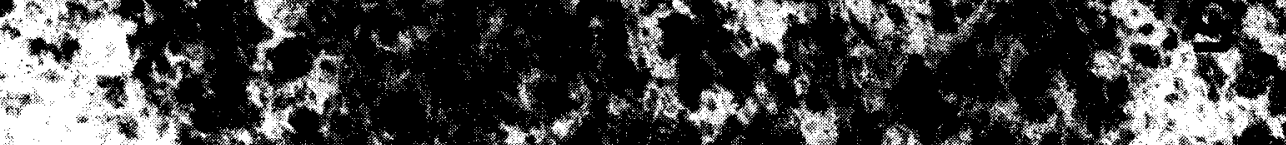

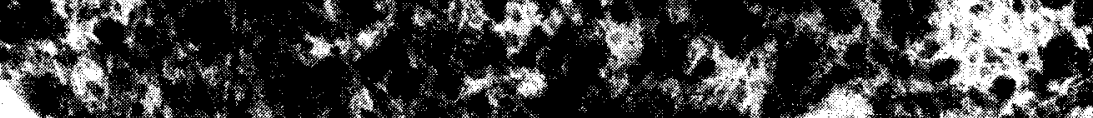

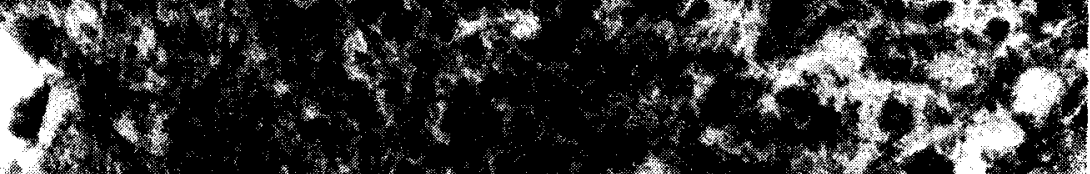

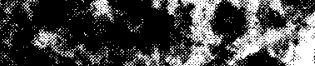

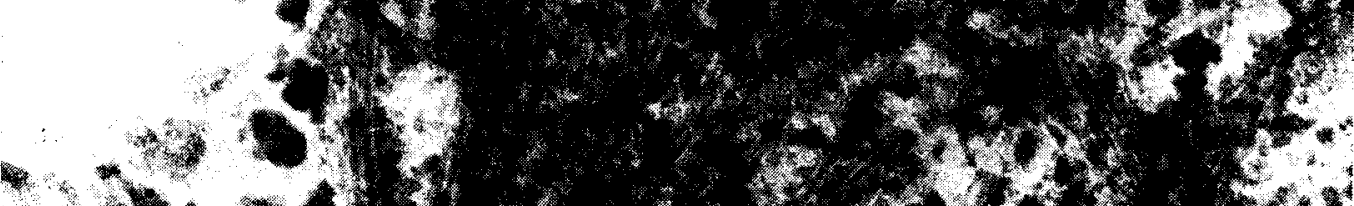

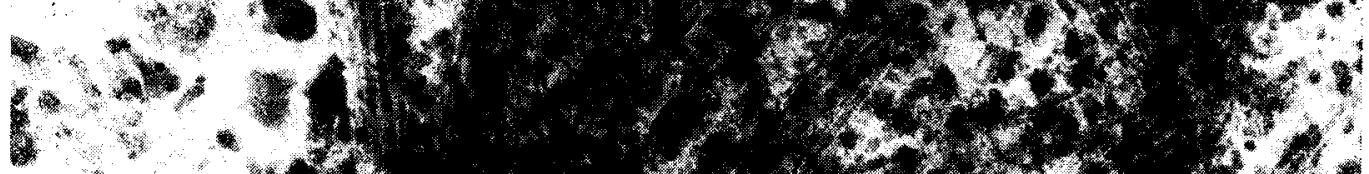

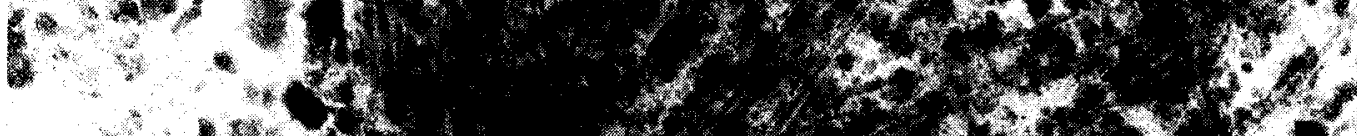

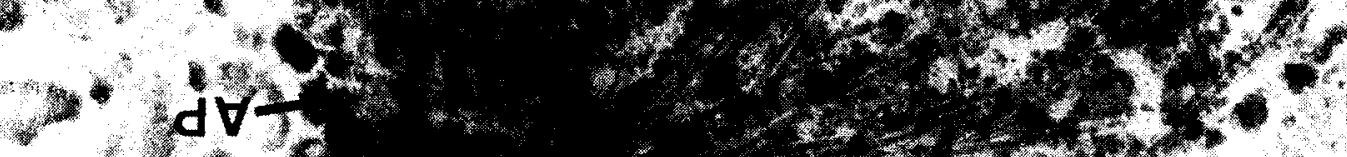

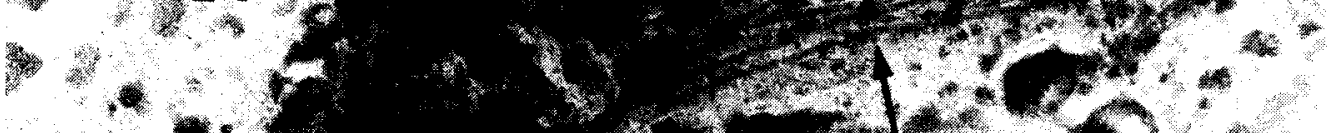
ats (3)

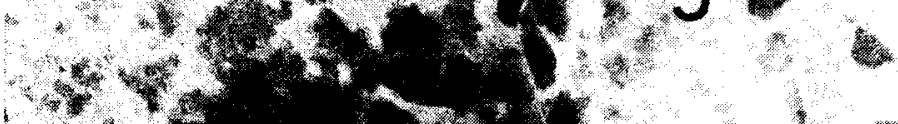
क्ष
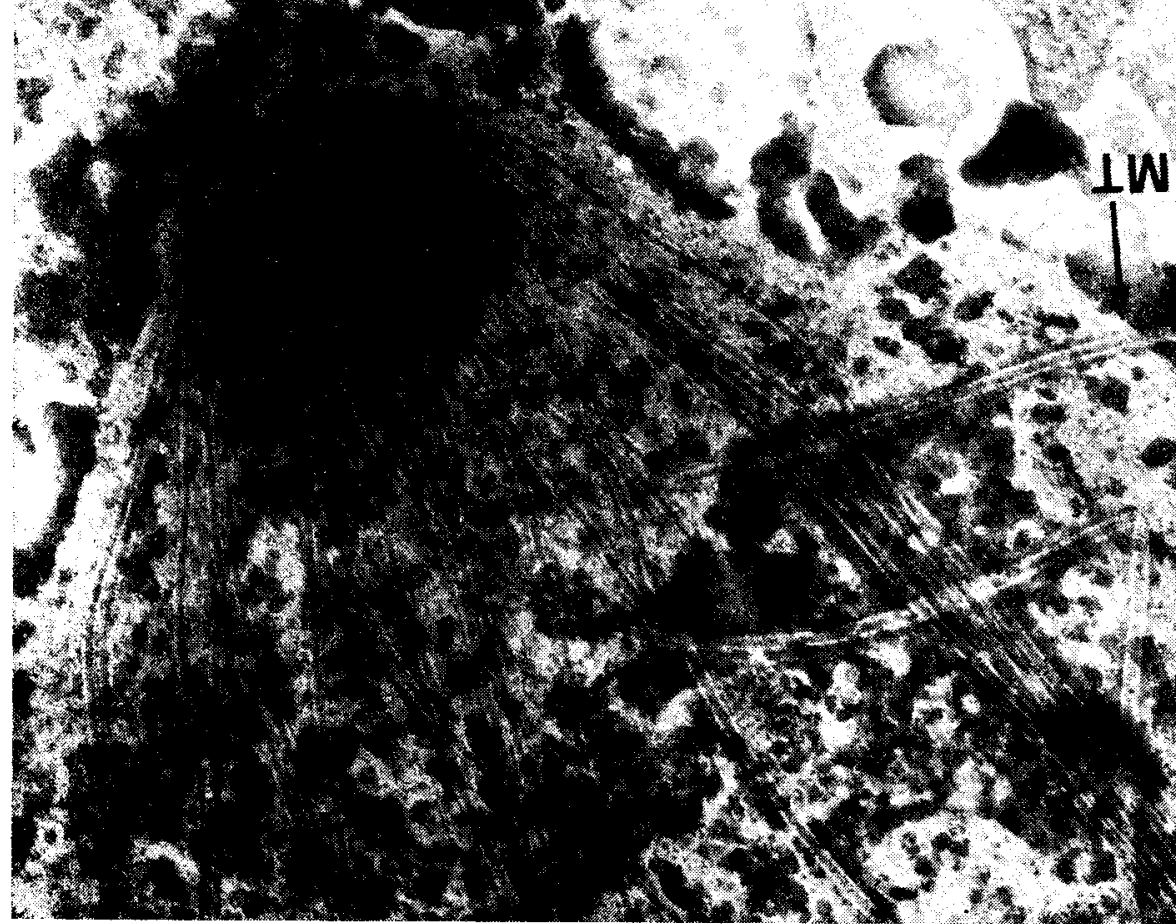
$e^{2}(1,6)$ 
Figura 5 - 2 Toxoplasma submetidos a choque osmótico e preparado pela técnica de coloração negativa com o ácido fosfotungstico $(4,5)$. Observa-se o complexo arranjo de microtúbulos (MT) constituindo o conoide (C). A partir do primeiro anel polar do concide (AP) 22 microtúbulos (MT) projetam-se para a regiăo posterior do parasito. Aumento: $60.000 \mathrm{x}$ 
Situado na região anterior do parasito e próximo ao núcleo, observam-se os sáculos e vesículas que constituem o complexo de Golgi. A sua localização nessa região tem duas implicações importantes: uma está ligada a seu papel secretor e que estaria relacionado com as roptrias, e a outra, ao seu papel na formação de membranas celulares e que teria relação com o processo de divisão do parasito, como será explicado oportunamente.

Além dessas estruturas descritas, o Toxoplasma apresenta um retículo endoplasmático predominantemente do tipo rugoso e localizado lateral e posteriormente ao núcleo. Ribossomos livres encontram-se distribuídos uniformemente por todo o citoplasma. Observa-se, também, a presença de mitocôndrias que apresentam cristas do tipo tubular, como encontradas em outros protozoários. Também se observam no citoplasma certos grânulos densos, vesículas plurimembranosas, vacúolos e grânulos de paraglicogênio, cujo significado físiológico não está estabelecido. Há tambśm certas estruturas que aparecem durante a divisão e que serão oportunamente descritas (Fig. 6).

\section{DIVISÃO DO TOXOPLASMA}

A maneira pela qual o Toxoplasma se multiplica tem sido motivo de grande discussão. Sempre prevaleceu a idéia de que ele se dividia pelo processo de fissão binária. Pereira de Castro verificou que em cultura de tecidos ocorre divisão esquizogônica e observou casos em que 32 núcleos haviam sido formados sem a divisão do citoplasma (35). Estudando o Toxoplasma em líquido peritoneal, através de métodos de impregnação pela prata, Goldman et al $(13,14)$ descreveram para o Toxoplasma gondii e Besnoitia jellisoni um processo $\mathrm{em}$ que havia a formação de dois parasitos filhos dentro de um, que eles denominaram de endodiogenia. O mesmo processo de divisão foi também descrito nas formas cisticas do Sarcoccystis tenella (44), onde além disso ocorre divisão binária, e em Frenkelia (M-Organism) (43).

Sheffield e Melton (50), estudando o Toxoplasma em cultura de células, ao microscópio eletrônico, sugerem que a endodiogenia seja o único processo de divisão que ocorre no Toxoplasma. Olisa (34) es- tudando o Toxoplasma no exsudato peritoneal, encontrou reprodução por fissão binária bem como um processo de divisāo múltipla do núcleo, semelhante à esquizogonia. Ela também descreveu um outro processo em que o parasito libera numerosas "células" contendo pequenos corpos aparentemente de origem nuclear. Ela sugere que este é um importante processo de reprodução, em que os corpos chamados de "morulae" são liberados na região do conóide. No entanto, este processo de divisão não encontra nenhum apoio na literatura sobre o assunto. Ela não encontrou imagens que sugerissem uma divisão por endodiogenia.

Resumindo podemos dizer que de um modo geral três tipos de divisão podem ser considerados para o Toxoplasma: (a) o processo de fissão binária, (b) endodiogenia e (c) a esquizogonia. A seguir será descrito cada um destes processos.

\section{DIVISÃO BINARIA}

Este era o tipo de divisão aceito pela maioria dos autores, antes dos trabalhos de Goldman et al $(13,14)$, descrevendo a endodiogenia. Segundo alguns autores, como Sheffield e Melton, tal tịpo de divisão não ocorre no Toxoplasma.

fí um processo de divisão onde há inicialmente uma divisão nuclear e a seguir, a divisão do citoplasma que ocorre graças a uma invaginação da membrana celular, com conseqüente formação de dois parasitos filhos que então se separam. Um exemplo típico é o que ocorre com as formas amastigotas intracelulares do Trypanosoma cruzi.

Segundo Vivier e Petitprez (52), no caso do Toxoplasma é apenas a membrana interna do parasito que se invagina e se insinua ao nível da constricção nuclear. A membrana externa permaneceria integra. Com a evolução do processo haveria uma situação semelhante ao que ocorre na endodiogenia, isto é, a existência de dois "parasitos filhos", delimitados por uma membrana espessa e envolvidos pela membrana externa do "parasito mãe". Os dois parasitos recém-formados, ao se liberarem, receberão a sua membrana externa de maneira semelhante ao que ocorre na endodiogenia. 


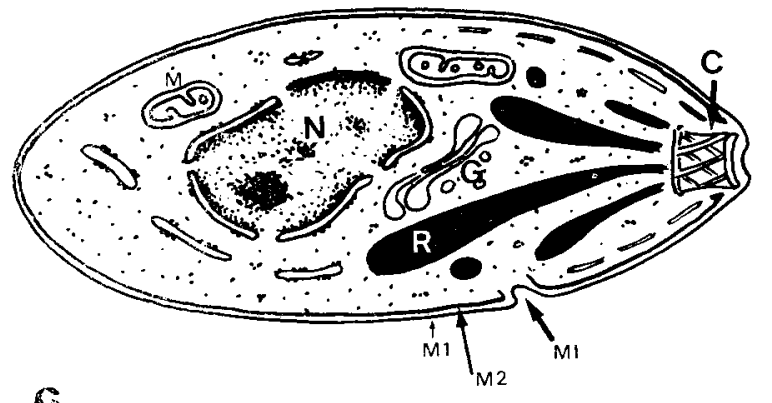

0

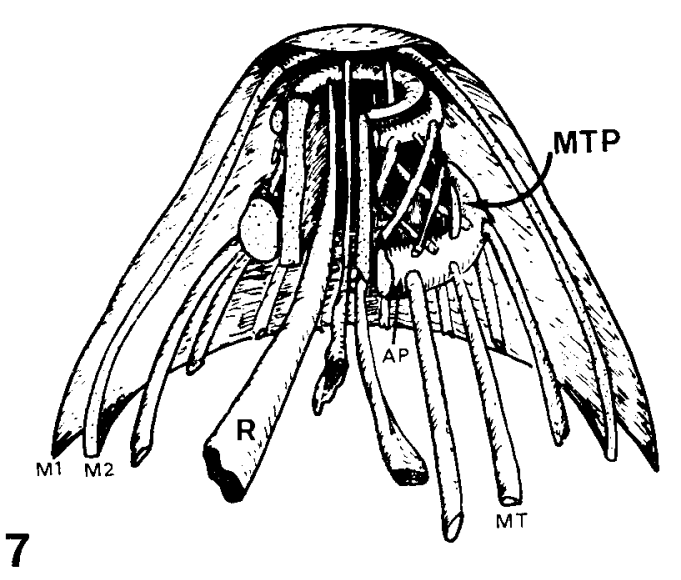

Fisura 6 - Esquema do Toxoplasma em interfase, mostrando a membrana externa ( $\left.\mathbf{M}_{\mathrm{i}}\right)$ e a interna ( $\left.\mathbf{M}_{,}\right)$, o "micropore" (MI), núcleo (N), complexo de Golgi (G), mitocôndria (M), roptrias (R) e o conoide (C).

Figura 7 - Esquema que mostra o complexo apical do Toxoplasma. $M_{1}$ e $M_{2}$ representam as membrinas externa e interna, respectivamente. O conoice (C) é vis cilínarica, cuja parede é constituída por microtúbulos (MTP). No interior do cilindro penetram as porçóes terminais das róptrias (R). Partincio do anel polar inferior do conoide (AP) saem os microtúbulos que projetam-se para a regiăo posterior do parasito (MT). 
Ainda não está claro se o processo de divisão binária realmente ocorre no Toxoplasma. possivel que as imagens interpretadas como sendo uma divisão binária. representem estágios de divisão por endodiogenia.

\section{ENDODIOGENIA}

o primeiro sinal de que o parasito vai entrar em divisão por endodiogenia é o aparecimento de duas zonas de Golgi, separadas e próximas à superficie anterior do núcleo. Sheffield e Melton (50) observaram próximo ao complexo de Golgi uma estrutura ovoide, homogênea, medindo aproximadamente $0,28-0,48 \mu \mathrm{m}$ por $0,8-1,0$ $\mu \mathrm{m}$, sendo envolvida por várias membranas. Tal estrutura é chamada de adjunto de Golgi. Às vezes é observado um aspecto de constricção nessa estrutura, sugerindo que ela se divide transversalmente. O par resultante se separa e as duas estruturas permanecem lateralmente situadas em relação ao núcleo. É possível que esta estrutura só exista nos parasitos em divisão.

Anteriormente ao núcleo aparecem uma ou mais estruturas circulares, de aspecto denso, envolvidas por membrana e com um diâmetro de cerca de $0,3 \mu \mathrm{m}$. Essas estruturas apresentam no seu interior áreas de menor eletrondensidade. É possível que representem os precursores das roptrias encontradas nos organismos filhos após se completar a divisão. Segundo Van der Zypen e Piekarski (56) nos dois polos anteriores do núcleo observa-se um corpo eletrondenso que foi identificado por métodos citoquímicos como sendo constituído por DNA, e chamado de "E-body" ( $\mathrm{E}=$ endodiogenia). Segundo estes autores, este corpo seria o indutor do processo de endodicgenia, que, sendo precocemente liberado do núcleo, iria constituir a matriz dos futuros núcleos. Estruturas semelhantes foram encontradas por outros autores que as interpretaram como sendo fragmentos do nucléolo.

Quando o "parasito filho" começa a se formar, aparece na porção anterior do "parasito mãe" uma membrana espessa que será a futura membrana interna do endozoita em formação (Fig. 3 e 8). Ela se acha próxima ao núcleo, que a esta altura está formando uma invaginação na membrana da sua face anterior, assumin- do assim uma forma bilobada. A membrana em formação se estende progressivamente no sentido posterior, à medida que o núcleo vai se estrangulando, englobando-o junto com porçōes citoplasmáticas do "parasito mãe" (Fig. 9). Já nas primeiras fases do aparecimento da membrana espessa observa-se a presença do conóide. Nesse primeiro estágio já há divisão do núcleo, que apresenta duas condensaçōes cônicas que formam o polo nuclear. A membrana nuclear permanece intacta durante a divisão, exceto nessas áreas polares. Imagens semelhantes foram observadas em Eimeria necatrix onde foi demonstrada a existência de microtúbulos constituindo um fuso $(7,8)$. E possivel que os microtúbulos que observamos em formas proliferativas do Toxoplasma e associados a uma placa eletrondensa, tenham sua origem no polo nuclear e constituam um fuso intranuclear (Meyer e de Souza, dados nāo publicados), à semelhança do que ocorre em outros protozoárias $(1,6,7,8,17,19)$.

A medida que a membranas nuclear se invagina e a membrana espessa se aprofunda, os dois' "parasitos filhos" vão tomando forma. Numa etapa posterior o núcleo se divide completamente e os dois parasitos já praticamente formados permanecem ainda ligados pela região posterior, separando-se posteriormente. Chegaremos a um estágio em que temos dois parasitos formados com todas as estruturas características do Toxoplasma, dentro do "parasito mãe" (Fig. 4). Nessa situação, às vezes se observa que o "parasito mãe" se apresenta em bom estado e com todas as organelas citoplasmáticas, inclusive o seu complexo apical.

Ainda não está claro o que acontece com os dois "parasitos filhos", dentro do "parasito mãe", até o momento de sua liberação. Caso a liberação ocorresse imediatamente, certamente restaria do "parasito mãe" considerável área citoplasmática. Quanto ao destino desta área temos duas possibilidades: a) se degeneraria, mas neste caso deveríamos encontrar dentro do vacúolo uma quantidade considerável de detritos celulares; b) segundo alguns autores, e o próprio Goldman et al $(13,14)$ em sua primeira descrição, há a possibilidade de que durante a divisão do núcleo ocorra a formaçáo de très fragmentos nucleares. Nesse caso teríamos a possibili- 


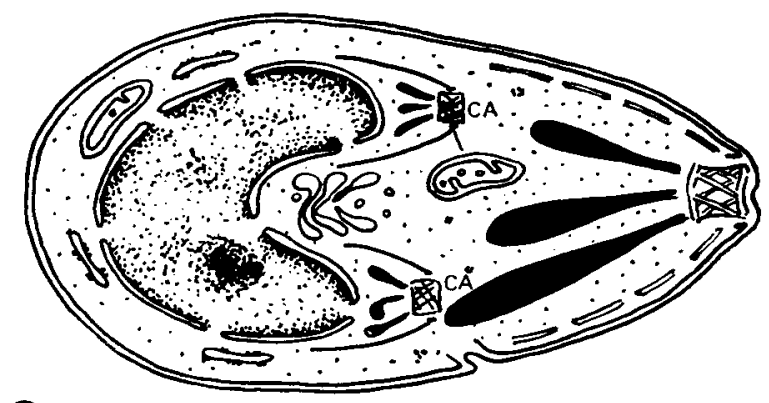

8

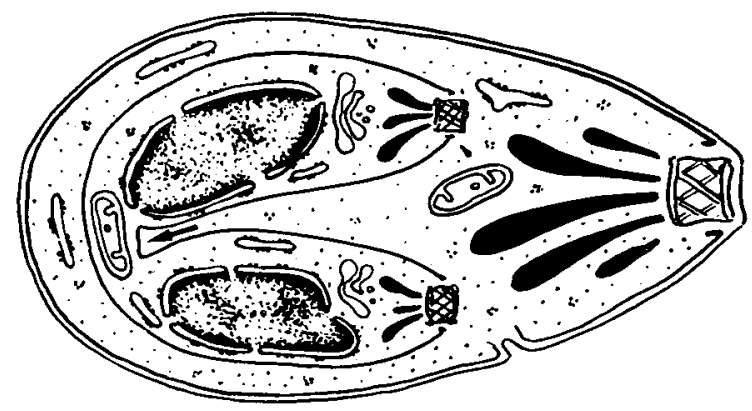

9

Figura 8 - Esquema que mostra uma fase inictal no processo de divisāo por endodiogenía. O núcleo do "parasito mãe" já apresenta uma invaginaçáo. Logo acima de cada polo, aparece o esboço do comp'exo apical (CA., $\mathbf{C A}_{y}$ ) dos "'parasitos filhos" em formaçăo.

Figura 9 - Fase mais adiantada co processo de divísão. Os dois "parasitos filhos" estāo quese formados porém unidos entre si pelo polo posterior $(\rightarrow)$. 
dade, considerada viável por Vivier $(53,54)$, de que, além da formação das duas céIulas filhas o "parasito mãe", dispondo de organelas citoplasmáticas e do núcleo, pudesse após a liberação dos "parasitos filhos", continuar uma vida autônoma, sendo inclusive capaz de se reproduzir novamente. No entanto admitindo-se a ocorrência deste tipo de divisão deveríamos encontrar nos vacúolos citoplasmáticos números ímpares de parasitos. O que se observa, porém, em cultura de tecidos é que o número de parasitos no interior de um vacúolo é sempre par e que cada parasito se divide dando origem a dois parasitos, que também se dividem dando origem a quatro e assim sucessivamente. $O$ mais provável é que após a formação dos dois "parasitos filhos", eles não sejam liberados imediatamente, permanecendo por algum tempo no interior do "parasito mãe", durante o qual eles aumentam de volume, de modo que ao se liberarem do "parasito mãe", este estivesse reduzido a pequena área que se desintegraria, dando origem às estruturas observadas no interior do vacúolo.

Em algumas ocasiões têm sido encontradas imagens em que se observa a presença de mais de dois núcleos dentro do parasito em divisão. Elas foram interpretadas por Vivier (53) como sendo um processo de divisão, em que há formação de mais de dois parasitos. Esse processo foi denominado de endopoligenia. Fm nosso material imagens semelhantes foram também encontradas, porém, com baixa freqüência (31).

O processo de liberaçāo dos parasitos recém-formados foi estudado por Vivier e Petitprez (32) que demonstraram que os "parasitos filhos" recebem a sua membrana externa a partir da membrana externa do "parasito mãe", a medida que vão se liberando pela região do complexo apical (Fig. 11) .

As imagens eletrônicas obtidas em Besnoitia jellisoni, Sarcocystis tenella e em Frenkelia mostram que a divisão por endodiogenia nestes proaozoários é semelhante à descrita para o Toxoplasma gondii $(43,44,45,46,47,49)$.

\section{ESQUIZOGONIA}

Vários autores têm relatado a existência do processo esquizogônico de divisão para o Toxoplasma bem como para Besnoitia jellisoni. Pereira de Castro (35) observou em cultura de tecidos casos em que o núcleo do parasito se dividia de modo a formar até mais de 32 núcleos, sem que houvesse divisão do citoplasma, o que caracteriza um processo esquizogônico de divisão. Gavin et al (12) interpretaram as imagens de rosáceas, obtidas ao microscópio eletrônico, como sendo uma célula multinucleada e que se assemelhava àquelas encontradas em parasitos da malária. Todavia, as observações iniciais de Ogino e Yoneda (33), confirmadas e ampliadas por Sheffield e Melton (50), demonstram que na realidade tais imagens não correspondem a uma esquizogonia, mas são resultantes de endodiogenias repetidas. Isso ocorre nos casos em que os endozoitos formados estejam paralelos ao eixo longitudinal do "parasito mâe" de modo que os vários "parasitos filhos" formados permanecem ligados entre si pela região posterior. Caso os endozoitas cresçam em direções variadas, eles se distribuem randomicamente no vacúolo e nesse caso não há a formação de rosáceas típicas.

Esquizogonia é um processo de formação de células filhas por fissão múltipla. Se as células filhas forem merozoitas, o processo pode ser chamado de merogonia; se forem esporozoitas, esporogonia e se forem gametas, gametogonia (24) . Como foi muito bem assinalado por Piekarski et al (37) todo o nosso conhecimento do processo de esquizogonia está baseado nos estudos clássicos realizados com o microscópio ótico. Os estudos mais recentes, feitos com o auxilio do microscópio eletrônico, têm fornecido maiores detalhes sobre este processo de divisão. Como exemplos clássicos de esquizogonia temos o que ocorre em parasitos da malária e em E:meria. No entanto, comparando estes dois grupos, observam-se diferenças significativas no processo de formação dos merozoitos. Em ambos os casos o núcleo se divide sucessivamente sem que haja divisão do citoplasma. No entanto, a maneira de como se inicia a formação dos parasitos filhos é diferente, por exemplo, na Eimeria callospermophili o início é semelhante ao que ocorre no processo de endodiogenia, observado no Toxoplasma, isto é, acima do núcleo forma-se uma membrana espessa que se estende progressivamente, englo- 


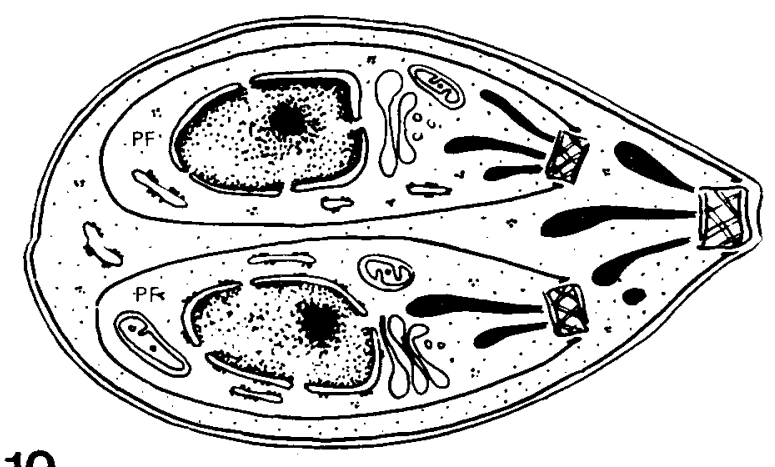

10

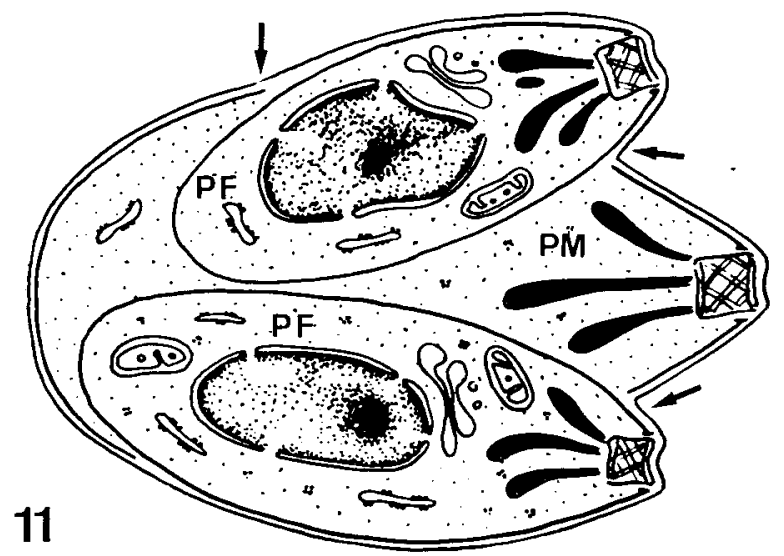

Figura 10 - Os dois parasitos filhos $\left(P_{4}\right.$ e $\left.P_{\Omega}\right)$ já completamente formados, no interior do "parasito mãe".

Figura 11 - Esquema que mostra a liberação dos parasitos filhos. A medicia que se projetam para fcra, recebem a membrana externa $\left(M_{*}\right)$ a partir da membrana externa do "parasito mãe" $(\rightarrow)$ 
bando partes do citoplasma do esquizonte, dando início à individualização do merozoito (38). O que temos observado na esquizogonia encontrada nas formas exoeritrocitárias do Plasmodium juxtanucleare (2) é diferente. Neste parasito forma-se uma membrana espessa, logo abaixo da membrana do esquizonte, e que se aprofunda no citoplasma do esquizonte incorporando núcleo e material citoplasmático, de modo a formar os merozoitas. No caso da Eimeria bovis (48), junto com a membrana espessa também aparece o conóide. Vale ressaltar que o Plasmodium juxtanucleare, bøm como todas as espécies de parasitos da malária, não apresenta um conóide típico.

Acreditamos que as imagens observadas nas formas proliferativas do Toxoplasma com o microscópio ótico e interpretadas como esquizogonia, representam rosáceas formadas por endodiogenias sucessivas em que os parasitos formados permanecem ligados entre si pela região posterior. Realmente tal aspecto poderia, à microscopia ótica, fazer supor que se trate de uma esquizogonia.

Gavian et al (12) bem como Sheffield e Melton (50) sugerem que a endodiogenia pode ser considerada como uma forma especial de esquizogonia. Realmente estes processos de divisão, ainda que diferindo quanto ao número de parasitos que se formam, apresentam algumas semelhanças, principalmente no caso da esquizogonia que ocorre em Eimeria callospermophili. Em trabalho recente com Eimeria tenella e Eimeria stiedae, Scholtyseck (42) considera a esquizogonia como um processo que apresenta duas diferentes fases. Na primeira fase ocorre divisão sucessiva do núcleo e depois aparecem fissuras que subdividem o esquizonte em compartimentos uninucleados, não inteiramente livres, chamados de citômeros. Na segunda fase, ocorrerá em cada citômero uma divısão por endodiogenia. Somente com este último processo de divicão é que haveria formação dos merozoitas. Baseado neste fato ele propôs a hipótese de que a endodiogenia é o processo primário e fundamental de reprodução assexuada nos coccídeos e possívelmente em todos os esporozoários. A esquizogonia seria um processo secundário de reprodução que se desenvolveu posteriormente.

\section{DIVISÃO NO INTESTINO DO GATO}

Já no caso das formas intestinais encontradas no ciclo gametogônico do Toxoplasma, no gato, Hutchinson et al (20) bem como Frenkel et al (10) e outros autores, demonstraram a presença de um processo esquizogônico de divisão. Em estudo ao microscópio eletrônico, Sheffield (51) confirmou estes resultados e observou que o esquizonte se desenvolve dentro de um vacúolo no interior da célula epitelial do intestino do gato. E envolvido por duas membranas, uma externa e uma interna. Não foi observada a presença de microtúbulos subpeliculares. No citoplasma encontram-se ribossomos livres, mitocôndrias com cristas tubulares e abundante retículo endoplasmático. Também se encontra uma região especializada, onde está situado o conóide. Após duas ou mais divisōes nucleares, começam a se formar os merozoitas de maneira semelhante ao que ocorre na endodiogenia. Forma-se a membrana espessa que progride englobando núcleo $\mathrm{e}$ porções do citoplasma. Estudo semelhante foi realizado por Piekarski et al (37) que no entanto, denominou este processo de divisão, de endopoligenia.

\section{CONSIDERAÇŌES FINAIS}

Ao final desta revisão, chegamos à conclusão de que pouco sabemos sobre a biologia do Toxoplasma gondii. Este protozcário dispõe de todas as organelas necessárias para uma existência independente bem como as enzimas da via glicolítica, do cizlo de Krebs e do sistema de citocromos. E capaz de sintetizar os diferentes tipos de RNA sem necessidade de estar no interior de uma célula. Apresenta um DNA quantitativamente semelhante ao encontrado entre os tripanosomídeos ou seja, cerca de 1,0 $\pm 0,2 \times 10-13$ gramas por parasito, concentração esta que é cerca de 50 vєzes menor que a encontrada $\mathrm{\epsilon m}$ uma célula hepática. Aparentemente o Toxoplas$m a$ não depende do citoplasma de uma célula hospedeira para sintetizar o seu DNA (36). No entanto, mesmo com todos estes dados, obtidos recentemente com a aplicação das técnicas de biologia molecular, continuamos sem ter uma hipótese sati fatória que explique a dependência celular deste parasito. 
Muito resta para ser esclarecido, quanto ao processo de divisão. Por exemplo, pouco sabemos sobre o processo de formação do conóide. Deve haver algum mecanismo que regule a sua formação. Resultados obtidos por Hammond and Danforth (18) em Eimeria magna, nos esquizontes de segunda geração em cultura de tecidos, mostraram um exemplo de "erro" na formação do complexo apical que consistiu na formaçāo em excesso dessas estruturas, que permaneceram sem serem aproveitadas, no corpo residual do esquizonte.

Achamos que a microscopia eletrônica, associada às modernas técnicas citoquímicas e imunocitoquímicas, que permitem a visualização de enzimas, antígenos e anticorpos ao nível ultraestrutural, muito poderá ajudar no esclarecimento de aspectos biológicos do Toxoplasma e na fisiopatogenia da toxoplasmose. Por outro lado torna-se necessário intensificar estudos bioquímicos sobre o parasito que, correlacionados com os dados morfológicos, poderão futuramente servir de base para o encontro de substâncias específicas com fins terapêuticos.

\section{AGRADECIMENTOS}

Aos Drs. Hertha Meyer, Marysa de Oliveira Musacchio, Raul Dodsworth Machado e Gerson Cotta Pereira pela contribuição prestada durante a preparação deste trabalho. Ao $\mathrm{Sr}$. Aderbal Alexandre Alves e a Sra. Nina Neal Shannon-Montgomery pelos auxílios técnicos e a Srta. Maria Helena Barbosa da Silva de Sá pelo trabalho de datilografia.

Ao Conselho de Ensino e Pesquisa da U.F.R.J., Conselho de Aperfeiçoamento do Pessoal de Nivel Superior (CAPES), Conselho Nacional de Pesquisa (CNPq), Fundação Gulbenkian e Banco Nacional do Desenvolvimento Econômico (BNDE Contrato FUNTEC 143) pelos auxílios condedidos aos Laboratórios de Cultura de Tecidos e Microscopia Eletrônica do Instituto de Biofísica da U.F.R.J.

\section{SUMMARY}

In this paper a general review is given on some biological aspects of Toxoplasma gondii, especially on the ultraestructure of the interphasic form ana the modifications which occur in the ultrastructure during the division of the parasite.

Initially the process of binary division has been discussed, admitting, however, that the images whish have been considered as binary division might represent stages of the division by endodiogeny.

The modifications are then described which occur in the fine structure of the "mother parasite" during the process of endodiogery, i.e. the formation of the 2 "daughter parasites" in its interior. This process is the same in Toxoplasma gondii, Besnoitia jellisoni, Sarcocystis tenella and Frenkelia.

The possibility is then discussed that "daughter parasites" are formed by the process of schizogony, as had been suggested by various authors. More recent results however show that schizogony does not exist in the vegetative forms of Toxoplasma gondii and that the images which were considered as such under the light microscope are the result of successive endodiogenies during which the newly formed endozoites remain united at their posterior region. Real schizogony, however, is found in the forms whish develop in the interior of the epithelial cells in the intestine of the cat, which is considered the final host of Toxoplasma gondii.

The concept of schizogony is then discussed, comparing this process in 3 different parasites as Eimeria bovis, Eimeria calospermophili and Plasmodium juxtanucleare which show certain differences in the initial phases of the individualization of the new parasites. The author then discusses the hypothesis which considers the endodiogeny the fundamental process of the division in Sporozoa, occuring at the final phase of schizogony. 
Finally, attention is given to the role which electron microscopy together with modern technigues of cytochemistry and immunocytochemistry might play to reach a better understanding of the biology of Toxoplasma gondii and the physiopathology of toxoplasmosis.

\section{REFERENCIAS BIBLIOGRÁFICAS}

1. AIKAWA, M.. HJJFF, C. G. \& SPRTNZ, H. - Fine structure of the assexual stages of Plasmodium elongatum. J. Cell Biol. 34: 227-2.50, 1967.

2. DE OLIVEIRA MUSACCHIO, M. DE SOUZA, W. - Plasmodium juxtanucleare: An electron microscopic study of the exoerythrocytic stages. "in press".

3. DE SOUZA, W. - Sobre o cultivo de alguns protomoários de vida in ${ }^{+}$racelular $\mathrm{em}$ cultura de tecidos. A Folha Médica 64: 503-510, 1972.

4. DE SOUZA, W. - Mise en év'donce et structure du système microtubulajre de Toxonlasma gondii. C. R. Acad. Sc. Paris 275: 2899-2901, 1972.

5. DE SOUZA, W. - Fine structure of the conoid of Toxoplasma gondii. Rev. Inst. Med. Trop. São Paulo. "in press".

6. DE SOUZA, W. \& MEYER, H. - On the fine structure of the nucleus in Trypanosoma cruzi in tissue forms, Splindle fib:r in the dividing nucleus. J. Protozool. "in press".

7. DUBREMETZ, J . F. - L'ultrastructure du centroile et du centrocône chez la coccidie Eimerix necatrix. Étude au cours de la schipognnie. Journal de Microscopie 12: 453-458, 1971.

8. DUBREMETZ, J. F. - Etude ultrastructurale de la mitose schizogonique chez la coccidie Eimeria necatrix (Johnson, 1930). J. Ultrastruct. Res. 42: $354-376,1973$.

9. FAYFR, R.. HAMMOND, D. M. CHOBOTAR, B. \& ELSNER. Y. Y. Cultivation of Besnoitin jellisoni in bovine cell culture. J. Parasit. 55: 645-653, 1969.

10. F'RENKEL, J.K., DUBEY J.P. \& MILLER, N. L - Toxoplasma gondii in cats: Fecal stages identified as coccidian oocysts Science 167: 893-896, 1970.

11. GARNHAM, P. C. C., BAKER, J. R. \& BIRD, R. G. - Fine structure of the cystic form of Toxoplasma gondii. Brit Med. J. 5271: 83-84, 1962.
12. GAVIN, M.A., WANKO, T. \& JACOBS, L. - Electron micro copo studies on reproducing and interkinetic Toroplasma. J. Protozool. 9: 222-234, 1862.

13. GOLDMAN, M., CARVER, R. K. \& SULZER, A. J. - Similar internal morphology of Toxoplasma gondii and Besnoitia jellisoni stained with silver protein. J. Parasit. 43: 490-491, 1957.

14. GOLDMAN, M., CARVER, R. K. \& SULZER, A. J. - Reproduction of $T O-$ xoplasma gondii by intornal budding. J. Parasit. 44: 161-171, 1958.

15. GUIMARĀES, F. N. \& MEYER, H. Cultivo de Toxoplasma (Nicolle et Manceaux, 1909) em cultura de tecido. Rev. Bras. Biol. 123: 126, 1942.

16. GUSTAFSON, P. V., AGAR H. D. \& GRAMER, D. S. - An electron microscope study of Toxoplasma gondii. Am. J. Trop. Med. Hyg. 3: 1008-1021, 1954.

17. HAMMOND. D. M., RORFRTS. W. L. YOTTSSET, N. N. \& DANFORTH. H. D. - F'ne structure of the intranuclear spindle poles in Eimeria callospermcn'ili and Eimeria magna. J. Parasit. 59: $581-584,1973$.

18. HAMMOND. D. M. \& DANFORTH, H. D. - Abnormal development of conoids in Eimeria magna. J. Parasit. 59: 585587, 1973.

19. HOWELLS, R.E. \& DAVIES, E.E. Nuclear division in the oocyst of Plasmodium berghei Ann. Trop. Med. Parasit. 65: 451-459, 1971.

20. HUTCHINSON, W. M., DUNACHIE, J. F., CHR - SIIM, J. \& YORK, K. Coccidianl.ke nature of Toxoplasma gondii. Brit. Med. J. 1: 142-144, 1970.

21. JADIN, J. M., CREEMERS, J. \& GIRouD, P. - Les stades initiaux $\mathrm{du}$ mcde de division binaire de Toxoplasma gondii. Nicolle et Manceaux, 1909. C. R. Acad. Sc. Faris. 268: 103$194,1969$. 
22. JONES, T C., YEH, S. \& HIRSCH, J. G. - The interaction between Toxoplasma gondi: and mammalian cells. I Mechanism of entry and intracellular fate of the parasite. J. Exp. Med. 136: 1157-1172, 1972 .

23. LEVADITI, C., SANCHIS-BAYARRI, V., LEPINE, P. \& SHOEN, R. - Étude sur l'encephalo-myélit? provoqué par le Tcxoplasma cuniculi. II - Essais de culture des Toxoplarmes en présence do ti sus in vitro. Ann. Inst. Pasteur. 43 : $80-86,1969$.

24. LEVINÉ, N. D. - Uniform terminolcgy for the protozoan sub-phylum apiccomplexa. J. Protozool. 18: 352$355,1971$.

25. LYCKE, E., LUND, E. \& STRAMNEGARD, O. - En'hancement by lysosyme and hyaluronidase of the penetration by Toxoplasma gondii into cultured host cells. Brit. J. Exp. Path. 46: 189-199, 1965 .

26. MEYER, H. \& XAVIER DE OLIVEIRA, M. - Resultados de 3 anos de observação de cultivo de Toxoplasma (Nicoile et Manceaux, 1909) em cultura de tecido. Rev. Bras. Biol. 5: 145$148,1945$.

27. MEYER, H. \& DE ANDRADE MENDONCA, I. - Electron microscopic observation of Toxoplasma "Nicolle et Manceaux" grown in tissue cultures. Para itology. 45: 449-451, 1955.

28. MEYER, H. \& DE ANDRADE MENDONÇA, I. - Electron microscopic observations of Toxoplasma "Nicolle et Manceaux" in thin sections of t:ssue cultures. Parasitology. 47: 66-69. 1957.

29. MEYER, H. \& DE OLIVEIRA MUSACCHIO, M. - Electron microscope study of the exoerythrocytic form of Plasmod um gallinaceum in thin sections of infected tis ue cultures. $J$. Protozool. 7: 22.2-228, 1960.

30. MEYER, H. \& DE OLIVEIRA MUSACCHIO, M. - An electron microscopic study of the final and jnitial forms of Plasmodium gallinaceum in thin sections of infected tissue cultures. J. Protozool. 12: 193-202, 1965.

31. MEYER, H. \& DE SOUZA, W. - Estudo ultra-microscópico do Toxoplasma gonáii em culturas de tecidos. An. Acad. Bras. Ci. 44: 584-585, 1972.

32. MEYER, H. \& DE OLIVEIRA MUSACCHIO, M. - Toxoplasma gondii in ti sue cultures. A microcinematographic study in phase contrast. Rev. Inst. Med. Trop. São Paulo. "in press".
33. OGINO, N. \& YONEDA, C. - The fine structure and mode of division of Toxoplasma gondii. Arch. Ophthal. 75: 218-227, 1966.

34. OLISA, E.E.G. - The fine structure of reproducing, Toxoplasma gondii. $\mathrm{Pa}-$ rasitology. 53: 643-649, 1963.

35. PERETRA DE CASTRO, M. - Divisão múltipla de Toxoplasma $\mathrm{\epsilon m}$ cultura de tocidos. Arq. Inst. Biol. 22: 233-240, 1955.

36. PERROTO, J., KEISTER, D. B. \& GELDERMAN, A. H. - Incorporation of precursor $_{\vec{j}}$ into Toxoplasma DNA. J. Protozool. 18: 470-473, 1971.

37. PIFKARSKI, G., PELSTER, B. \& WITTE, H. M. - Endopolygenie bei Toxoplasma gondii. Z. Paras.tenk. 36: 122-130, 1971.

38. ROBERTS, W. L.. HAMMOND, D. M., ATDERSON, L. C. \& SPEER C. A. IItrastructural study of Schizogony in Eimeria callospermophili. J. Protozool. 17: 584-592, 1970.

39. RUDZINSKA, M. A., TRAGER, W. \& BRAY, R. S. - Pinocytotic uptake and the digestion of hemoglobin in malarial parasites. J. Protozool, 12: 563576, 1965.

40. SABIN, A. B. \& OLTTSKY, P. K. Toxoplasma and obrigate intracellular parasitism. Science. 85: 336-338, 1937.

41. SCHOLTYSECK, E. \& MELHORN, H. - Ultrastructural study of characteristic organelles (Paired organelles, Micronemes, Micropores) of sporozoa and related organisms. Z. Parasitenk 34: 97-127, 1970 .

42. SCHOLTYSECK, E. - Die deutung von Endodyogenie und schizogonie bei Coccidien und anderen sporozoen. $\mathbf{Z}$. Parasitenk. 42: 87-104, 1973.

43. SCHOLTYSEK E., MELHORN, H. \& MỨLLER, E. G. - Identifikation von Merozoiten der vier cystenbildenden Coccidien (Sarcocytis, Toxoplasma, Besnoitia, Frenkelia) auf grund feinstruktureller kriterien. $\mathrm{Z}$. Parasitenk. 42: 185-206, 1973.

44. SÉNAUD, J. - Les modalités de la multiplication des éléments cellulaires dans le kystes de la sarcoporidie du mouton (Sarcocytis tenella Railliet, 1886) . C. R. Acad. Sc. Paris. 256: 10091011,1963

45. SENAUD, J. - Contribution à l'étude des Sarcosporidies et des Toxoplasmes (Toxoplasma) . Protistológica. 3: 167$-232,1967$. 
46. SENAUD, J. - Sur l'ultrastructure des kystes de Besnoitia jellisoniFrenkel 1953 - (spornzoa, Toxoblasma) chez le souris (Mus musculus). C. R. Sc. Paris, 268: 816-819, 1969.

47. SHEFFIELD, H. G. - Electron microscopic study, of the proliferate form of Besnoutia jellisoni. J. Parasit. 52: 583-594, 1966.

48. SHEFFIELD, H. G. \& HAMMOND, D. M. - Electron microscope observations on the development of first generation merozoites of Eimeria bovis. J. Parasit. 53 : 831-840, 1967 .

49. SHEFFIELD, H. G. - Observations on the fine estructure of the "cyst stage" of Besnoitia jellisoni. J. Protozool, 15: 685-693, 1968.

50. SHEFFIELD, H. G. \& MELTON, M. L. - The fine structure and reproduction of Toxoplasma gondii. J. Parasit. 54: 209-226, 1968.

51. SHEFFIELD, H. G. - Schizogony in Toxoplasma gondii. An electron microscope study. Proc. Helminthol. Soc. Wash. 37: 237-242, 1970.
52. VIVIFR, E. \& PETITPREZ, A - Le complexe membrainaire superficiel et son evolution lors de l'elaboration des individu; fils chez Toxoplasma gondii. J. Cell Biol. 43: 329-342, 1968.

53. VIVIER, E. - Observations nouvelles sur la reproduction assexuée de Toxoplasma gondii et considérations sur la notion d'endogenèse. C. R. Acad. Sc. Paris, 271: 2123-2126, 1970.

54. VIVIER, E. - Variabilité des processus de reproduction vegetative de Toxoplasma gondii chez la souri:. Comptes Rendus ler Multicolloque Europeen de Parasitologie. Rennes, I au 4 septembre, 1971.

55. VIVIER, E. \& PETITPREZ, A. - Données ultrastructurales complémentaires, morphologiques et cytochimiques, sur Toxoplasma gondii. Protistologica. 8: 199-221, 1972.

56. ZYPEN, E. VAN DER \& PIEKARSKI, G. - Die endodyogenie bei Toxoplasma gondii. Eine morphologische Analyze. Z. Parasitenk. 29: 15-36, 1967. 